\title{
Pearls \& Oy-sters: No-cutoff large vessel occlusion stroke
}

\section{An indication for thrombectomy that can be missed}

Kunakorn Atchaneeyasakul, MD, Sushanth Aroor, MD, Marie-Christine Brunet, MD, Priyank Khandelwal, MD, Vasu Saini, MD, Sebastian Koch, MD, and Dileep Yavagal, MD

Neurology ${ }^{\circledR}$ 2019;93:1014-1015. doi:10.1212/WNL.0000000000008575

\section{Pearls}

- Large vessel occlusion (LVO) stroke with the proximal end of the thrombus located at a branch point may present with no cutoff on $\mathrm{CT}$ angiogram imaging.

\section{Oy-sters}

- LVOs presenting with no cutoff on CT angiogram imaging are usually in the smaller branch such as the M2 or M3 branch of the middle cerebral artery (MCA) and can still cause a large perfusion deficit and disabling symptoms.

- $\quad 3 \mathrm{D}$ angiography may be useful for patients presenting clinically with LVO to find subtle occlusions missed on CT angiography (CTA).

A 79-year-old man presented with left hemibody weakness, right gaze preference, and left side neglect on awakening, last known well approximately 6-8 hours prior to emergency department arrival. Noncontrast CT brain did not demonstrate any acute intracranial hemorrhage and Alberta Stroke Program Early CT Score (ASPECTS) score of 10. IV tissue plasminogen activator was not considered due to the patient presenting outside the treatment window. A CT angiogram head was unable to identify LVO (figure 1, A and B). Due to high clinical suspicion of LVO despite negative CT angiogram, a CT perfusion head was performed, demonstrating a large area of elevated time to peak and decreased cerebral blood flow, with relatively unchanged cerebral blood volume in the right MCA territory, involving posterior frontal, parietal, and temporal lobe (figure 1C). Catheter angiogram showed all 3 major branches of the MCA with no vessel stump or cutoff but there was an area of paucity of

Figure $1 \mathrm{CT}$ angiogram and perfusion
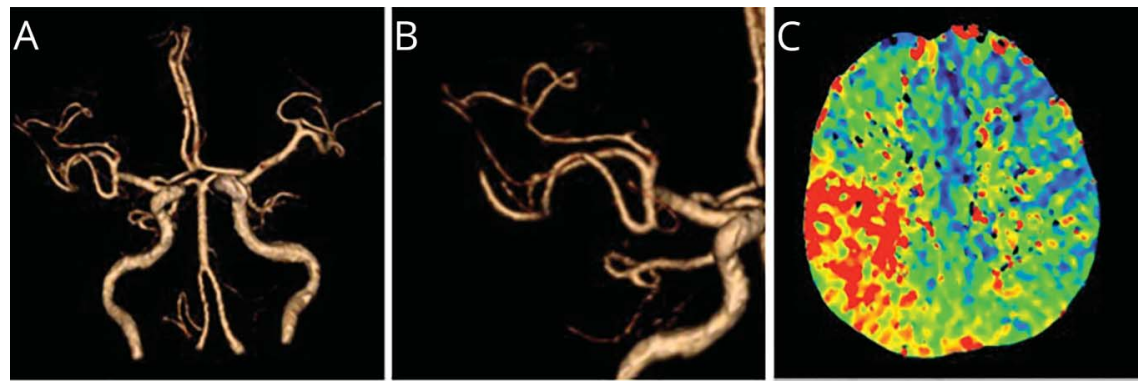

(A, B) 3D reconstruction of CT angiogram of the head shows filling of middle cerebral artery (MCA) branches. (C) CT perfusion image shows area delayed time to peak portion of the right MCA territory.

From the Departments of Neurology (K.A., S.A., V.S., S.K., D.Y.) and Neurosurgery (M.-C.B., P.K., D.Y.), University of Miami Miller School of Medicine, FL.

Go to Neurology.org/N for full disclosures. Funding information and disclosures deemed relevant by the authors, if any, are provided at the end of the article. 


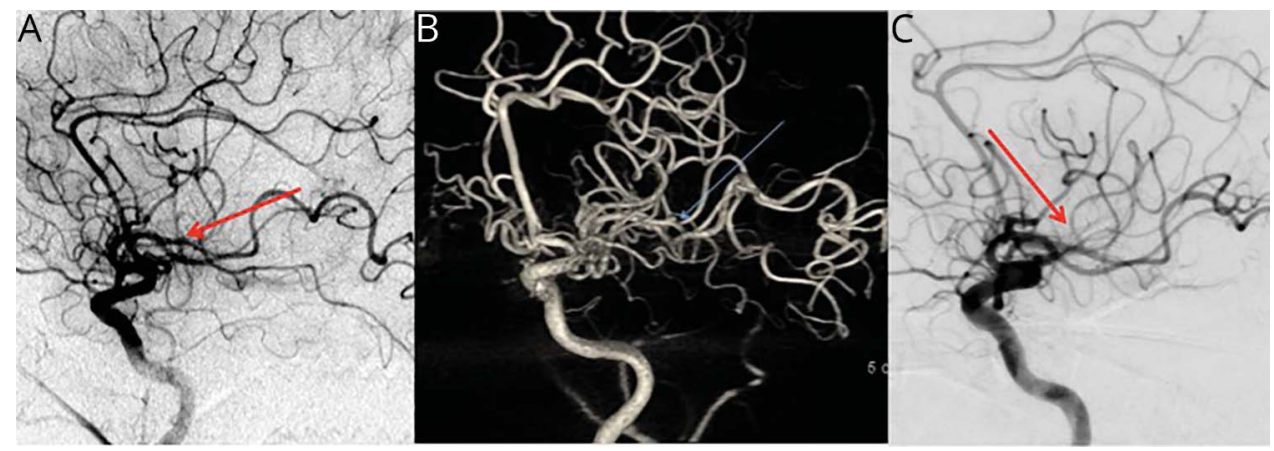

(A) Prethrombectomy angiogram shows area of paucity of vasculature in the right middle cerebral artery territory with no stump of vessel cutoff. (B) Rotational angiography with 3D reconstruction shows a visible vessel stump or cutoff (blue arrow). (C) Post thrombectomy angiogram shows complete filling of the occluded artery branch.

vasculature in the MCA distribution (figure 2A). 3D rotational imaging of right internal carotid artery was performed during the catheter angiography (figure 2B) and a suspected occlusion of one MCA branch was identified. Supraselective angiography was performed, utilizing microcatheter combined with microguidewire placed distal to the suspected occlusion. This confirmed the M3 branch of the inferior division of right MCA occlusion. Stent-retriever thrombectomy achieved full recanalization with modified thrombolysis in cerebral infarction score 3 noted on catheter angiography (figure 2C). Prior to discharge, the patient had substantial neurologic improvement with residual minimal left hemiparesis.

\section{Discussion}

LVO acute ischemic stroke of the anterior circulation may result in significant disability and rapid revascularization with mechanical thrombectomy is now the standard of care within the treatment window. Randomized trials of mechanical thrombectomy with novel stent-retriever have reported safety and efficacy of mechanical thrombectomy up to 24 hours after symptom onset. ${ }^{1,2}$

However, LVO with the proximal end of the thrombus located at a branch point may present with no cutoff, with the stump not being visible on angiographic imaging, including CTA, magnetic resonance angiography, and digital subtraction angiography, as in this case, and the target for mechanical thrombectomy may not be clear. This entity is not well described and the indication for emergent thrombectomy may be missed.

LVOs presenting with no cutoff that can be missed are usually M2 or M3 branches of the MCA. Recent studies are increasingly demonstrating the safety of endovascular treatment for M2 occlusions ${ }^{3,4}$ with recent consideration to treat M3 occlusions on a case by case basis. ${ }^{5}$ While CT angiography traditionally has been used to diagnose LVO in acute ischemic stroke, the sensitivity for more distal occlusions is uncertain.
Multiphase CTA has been noted to increase sensitivity in detecting LVOs over single-phase CTA, ${ }^{6}$ while the role of including $\mathrm{CT}$ perfusion has not been well studied.

In cases with high clinical suspicion of LVO, additional imaging such as $\mathrm{CT}$ perfusion or magnetic resonance perfusion should be pursued in order to identify patients with significant cortical area of mismatch/low perfusion indicating a potential LVO not seen on standard vessels imaging. Furthermore, a rotational angiogram with $3 \mathrm{D}$ reconstruction can show the hidden cutoff vessel and identify the origin of the occluded branch to guide navigation, as in our case.

\section{Author contributions}

All authors: conception and design, acquisition, analysis and interpretation of data, and review of submitted version of manuscript. K. Atchaneeyasakul: drafting the article. K. Atchaneeyasakul, M.-C. Brunet, D. Yavagal: critical revision of article.

\section{Study funding}

No targeted funding reported.

\section{Disclosure}

The authors report no disclosures relevant to the manuscript. Go to Neurology.org/N for full disclosures.

\section{References}

1. Nogueira RG, Jadhav AP, Haussen DC, et al. Thrombectomy 6 to 24 hours after stroke with a mismatch between deficit and infarct. N Engl J Med 2018;378:11-21.

2. Albers GW, Marks MP, Kemp S, et al. Thrombectomy for stroke at 6 to 16 hours with selection by perfusion imaging. N Engl J Med 2018;378:708-718.

3. Powers WJ, Derdeyn CP, Biller J, et al. 2015 American Heart Association/American Stroke Association focused update of the 2013 guidelines for the early management of patients with acute ischemic stroke regarding endovascular treatment: a guideline for healthcare professionals from the American Heart Association/American Stroke Association. Stroke 2015;46:3020-3035.

4. Sarraj A, Sangha N, Hussain MS, et al. Endovascular therapy for acute ischemic stroke with occlusion of the middle cerebral artery $\mathrm{m} 2$ segment. JAMA Neurol 2016;73:1291-1296.

5. Mokin M, Ansari SA, McTaggart RA, et al; Society of NeuroInterventional Surgery. Indications for thrombectomy in acute ischemic stroke from emergent large vessel occlusion (ELVO): report of the SNIS Standards and Guidelines Committee. J Neurointerv Surg 2019;11:215-220.

6. Menon BK, d'Esterre CD, Qazi EM. Multiphase CT angiography: a new tool for the imaging triage of patients with acute ischemic stroke. Radiology 2015;275: $510-520$ 


\section{Neurology}

\section{Pearls \& Oy-sters: No-cutoff large vessel occlusion stroke: An indication for thrombectomy that can be missed}

Kunakorn Atchaneeyasakul, Sushanth Aroor, Marie-Christine Brunet, et al. Neurology 2019;93;1014-1015

DOI 10.1212/WNL.0000000000008575

This information is current as of December 2, 2019

\section{Updated Information \&} Services

References

Subspecialty Collections

Permissions \& Licensing

Reprints including high resolution figures, can be found at: http://n.neurology.org/content/93/23/1014.full

This article cites 6 articles, 2 of which you can access for free at: http://n.neurology.org/content/93/23/1014.full\#ref-list-1

This article, along with others on similar topics, appears in the following collection(s):

All Cerebrovascular disease/Stroke

http://n.neurology.org/cgi/collection/all_cerebrovascular_disease_strok $\mathrm{e}$

CT

http://n.neurology.org/cgi/collection/ct

Information about reproducing this article in parts (figures,tables) or in its entirety can be found online at:

http://www.neurology.org/about/about_the_journal\#permissions

Information about ordering reprints can be found online:

http://n.neurology.org/subscribers/advertise

Neurology ${ }^{\circledR}$ is the official journal of the American Academy of Neurology. Published continuously since 1951, it is now a weekly with 48 issues per year. Copyright () 2019 American Academy of Neurology. All rights reserved. Print ISSN: 0028-3878. Online ISSN: 1526-632X.

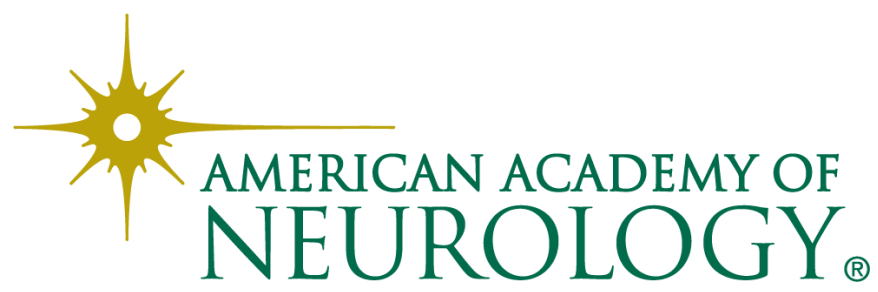

